This item was submitted to Loughborough's Research Repository by the author.

Items in Figshare are protected by copyright, with all rights reserved, unless otherwise indicated.

\title{
Healthcare workers' perspectives on participatory system dynamics modelling and simulation: Designing safe and efficient hospital pharmacy dispensing systems together
}

\section{PLEASE CITE THE PUBLISHED VERSION}

https://doi.org/10.1080/00140139.2020.1783459

\section{PUBLISHER}

Taylor and Francis

\section{VERSION}

AM (Accepted Manuscript)

\section{PUBLISHER STATEMENT}

This is an Accepted Manuscript of an article published by Taylor \& Francis in Ergonomics on 13 July 2020, available online: https://doi.org/10.1080/00140139.2020.1783459

\section{LICENCE}

CC BY-NC-ND 4.0

\section{REPOSITORY RECORD}

Ibrahim-Shire, Mohammed, Gyuchan Thomas Jun, and Stewart Robinson. 2020. "Healthcare Workers' Perspectives on Participatory System Dynamics Modelling and Simulation: Designing Safe and Efficient Hospital Pharmacy Dispensing Systems Together". Loughborough University. https://hdl.handle.net/2134/12543299.v1. 


\section{Healthcare Workers' Perspectives on Participatory System Dynamics}

Modelling and Simulation: Designing Safe and Efficient Hospital

Pharmacy Dispensing Systems Together

Mohammed Ibrahim Shire ${ }^{\text {ac }}$, Gyuchan Thomas Jun ${ }^{\mathrm{a}}$, Stewart Robinson ${ }^{\mathrm{b}}$

${ }^{a}$ Design School, Loughborough University, Loughborough, UK

${ }^{b}$ School of Business and Economics, Loughborough University, Loughborough, UK

${ }^{c}$ Presently at Institute of Criminal Justice Studies, University of Portsmouth,

Portsmouth, UK 
With increasingly complex safety-critical systems like healthcare being developed and managed, there is a need for a tool that permits decision-makers to better understand the complexity, test various strategies and guide effective changes. System Dynamics (SD) modelling is an effective approach that can aid strategic decision-making in healthcare systems but has been underutilised partly due to the challenge of engaging healthcare stakeholders in the modelling process. This paper, therefore, investigates the applicability of a participatory SD approach based on healthcare workers' perspectives on ease of use (usability) and usefulness (utility). The study developed an interactive simulation dashboard platform which facilitated participatory simulation for exploring various hospital pharmacy staffing level arrangements and their impacts on interruptions, fatigue, workload, rework, productivity and safety. The findings reveal that participatory SD approach can enhance team learning by converging on a shared mental model, aid decision-making and identifying trade-offs. The implications of these findings are discussed as well as experience and lessons learned on modelling facilitation.

Keywords: participatory modelling, computer simulation, pharmacy dispensary, healthcare, group-model-building

Practitioner Summary: This paper reports the perspectives of healthcare workers, who were engaged with a participatory system dynamics modelling and simulation process for hospital pharmacy staffing level management. Evaluative feedback revealed that the participatory SD approach can be a valuable tool for participatory ergonomics by helping the participants gain a deeper understanding of the complex dynamic interactions between workload, rework, safety and efficiency. 


\section{Introduction}

Healthcare systems are confronted with challenges such as increasing demand for healthcare service, shortage of healthcare workforce, higher patient expectations, increased staff turnover, growing healthcare costs, and limited resources (Faezipour and Ferreira 2013; Mutingi and Mbohwa 2012), whilst dealing with multiple and competing goals like safety, efficiency and financial sustainability. These multiple challenges and goals add to the intricacy of managing and designing healthcare systems.

Hollnagel's ETTO (Efficiency-Thoroughness Trade-Off) principle (2009) highlights the importance of a good balancing act between two competing goals, efficiency and thoroughness in managing complex systems. The trade-off, when cost reduction and efficiency gain are the dominant concern, may favour efficiency over safety. Similarly Dul et al. (2012) argue that human factors studies should take into account multiple outcomes: from safety and worker well-being to productivity, efficiency and organisation performance, but few studies and improvement works have considered multiple outcomes and their relationships using computational modelling approaches.

Considering multiple outcomes for complex system design benefits from the involvement of all relevant stakeholders and the inclusion of their input (Hettinger et al. 2015; Underwood, Waterson, and Braithwaite 2016; Jun et al. 2018). Evidence also suggests that involving the various stakeholders in the improvement of health services is challenging but can lead to more responsive and efficient services (Fisher 2011; NESTA 2013). Group model-building and simulation approaches have the potential to overcome these challenges by establishing a sense of ownership and group trust from the start (Vennix 1999; Vennix et al. 1992). 


\section{Participatory System Dynamics (SD) Modelling}

System Dynamics (SD) simulation is a computational modelling approach that can be utilised as a toolkit to address human factors (e.g. workload, fatigue, error) and complex system issues (e.g. safety, productivity, rework) (Ibrahim Shire, Jun, and Robinson 2018; Salmon and Read 2019; Hettinger et al. 2015). It can model the dynamic interactions in the complex healthcare systems and give decision-makers a better understanding of how the systems work (Ibrahim Shire et al. 2019) and how the behaviour of a system changes over time. However, the SD approach has made a low impact possibly due to low involvement from the operational staff (T Eldabi, Paul, and Young 2006; Tillal Eldabi 2009; Brailsford 2005). Equally, the impact of the SD method in healthcare settings is limited (Atkinson et al. 2015; Proudlove, Black, and Fletcher 2007).

Participatory SD modelling and simulation, which engages a broad group of stakeholders in the process of system modelling and simulation, can involve relevant healthcare staff in defining problems, making decisions and impact. Participatory SD modelling can use a deliberative group process (Pesce, Kpaduwa, and Danis 2011) to build visual and computational models that allow decision-makers to illustrate factors that generate and affect the structural and dynamic properties of the system. The decision makers can then use these models to theorise and simulate the likely effects of specific interventions anticipated to improve system behaviour and achieve healthcare goals (Foster-Fishman and Behrens 2007; Stave 2002; Zimmerman et al. 2016a). Whilst stakeholders were included in the model development (Atkinson et al. 2015; Voinov et al. 2016; Gilbert et al. 2018), the participants' perspectives on the utility and usability of the participatory SD approach have been seldom evaluated (Jones et al. 2009), more specifically in the healthcare domain (Fone and Hollinghurst 2003; Katsaliaki and Mustafee 2011). 
The adoption of participatory SD approach in healthcare has significantly lagged behind other sectors, such as the business industry and environmental sciences (Jahangirian et al. 2012). Scholars have argued that this is partly due to limited interaction and engagement with healthcare stakeholders in the participatory model development (Atkinson et al. 2015; Seidl 2015; Jahangirian et al. 2012; Young et al. 2009).

This paper attempts to apply a participatory SD approach to staffing level management in a UK hospital pharmacy setting taking into account multiple outcomes including well-being of healthcare workers (workload and fatigue), safety (dispensing error) and productivity (backlog and rework). The outcomes of the simulation has been published elsewhere (Ibrahim Shire et al. 2019), but it is important to ensure that this approach is both useful and usable, if it is really to be used to improve the design/decision making (Stanton and Young, 1999). Several scholars have also identified the need to evaluate the participants' learning process in participatory SD modelling (Voinov and Bousquet 2010; Hewitt, Delden, and Escobar 2014). Presently, no standardised protocols exists that determines the success of a participatory SD approach, but some have suggested interviews, surveys, and questionnaires as appropriate tools to evaluate the approach (Voinov and Bousquet 2010).

The main purpose of this study is to investigate perspectives of healthcare workers who were involved in participatory SD modelling and simulation. The investigation takes the form of a case-study of the use of participatory SD approach at hospital pharmacies. Based on questionnaire, semi-structured interviews with twenty one participants, and observation of multiple sessions, we report on their perceptions of the utility and usability of participatory modelling and simulation as a tool for the 
decision support for managing staffing levels. We also identify practical lessons on how to facilitate a model-building session in healthcare.

\section{Methods}

\section{Context}

This paper is based on a case study that adopted a participatory SD approach to explore the impacts of staffing level management on safety and productivity in a hospital pharmacy. Medication errors have been one of the major factors contributing to harmful events that endanger patient safety (Cousins, Gerrett, and Warner 2012; Service 2018) There is growing evidence that signifies that frequent dispensing errors and the high workload of pharmacists are interlinked (Jacobs, Johnson, and Hassell 2018). The most cited reason has shown to be high workload (Schafheutle, Seston, and Hassell 2011) whilst poor handwriting, insufficient staff, interruptions and inadequate skill-mix have also been significantly mentioned for assisting to increased dispensing errors (Schafheutle, Seston, and Hassell 2011; James et al. 2009). Berwick's report (2013) identifies the need for applying a systematic approach in setting the right staffing level that is grounded on a dynamic overview of existing staff capacity.

The case study followed the overall participatory processes (stakeholder interviews, group model building and focus groups) as described in Table 1. This paper reports on the results of the evaluation (Stage 4 in Table 1) of the participatory SD approach experienced by the participants through Stage 1-3. The modelling and simulation results from Stage 1-3 are described more fully elsewhere (Ibrahim Shire et al. 2019; Ibrahim Shire 2018). 
Table 1 Participatory SD approach of the hospital pharmacy project

\begin{tabular}{|c|c|c|c|}
\hline Stage & Methods & Participants & Outputs \\
\hline $\begin{array}{l}\text { 1. Model } \\
\text { conceptualisation }\end{array}$ & $\begin{array}{c}\text { Preliminary } \\
\text { stakeholder } \\
\text { interviews } \\
\text { (semi-structured) }\end{array}$ & $\begin{array}{l}9 \text { participants in total } \\
\text { (2 administrators; } 4 \\
\text { dispensers; } \\
3 \text { checkers) }\end{array}$ & $\begin{array}{l}\text { Pharmacy workflow } \\
\text { Identification of multiple factors } \\
\text { affecting hospital pharmacy work }\end{array}$ \\
\hline \multirow[t]{4}{*}{$\begin{array}{l}\text { 2. Model } \\
\text { development }\end{array}$} & $\begin{array}{l}\text { Stakeholder } \\
\text { workshop (group } \\
\text { model building) }\end{array}$ & \multirow[t]{4}{*}{$\begin{array}{c}13 \text { participants in total } \\
\text { (4 dispensers; } \\
7 \text { trainees; } \\
2 \text { checkers) }\end{array}$} & $\begin{array}{l}\text { Initial qualitative model (causal } \\
\text { loop diagram) }\end{array}$ \\
\hline & $\begin{array}{c}\text { Stakeholder } \\
\text { interviews } \\
\text { (semi-structured) }\end{array}$ & & $\begin{array}{c}\text { Refined qualitative model (causal } \\
\text { loop diagram) }\end{array}$ \\
\hline & $\begin{array}{c}\text { Stakeholder } \\
\text { interviews } \\
\text { (semi-structured) } \\
\end{array}$ & & $\begin{array}{l}\text { Quantitative model (stock-flow } \\
\text { diagram) }\end{array}$ \\
\hline & $\begin{array}{l}\text { Custom simulation } \\
\text { dashboard } \\
\text { development } \\
\text { (Forio-based) }\end{array}$ & & $\begin{array}{c}\text { Web-based interactive simulation } \\
\text { dashboard for scenario testing }\end{array}$ \\
\hline $\begin{array}{l}\text { 3. Scenario } \\
\text { testing }\end{array}$ & $\begin{array}{l}\text { Focus group } \\
\text { discussions }\end{array}$ & \multirow{2}{*}{$\begin{array}{l}21 \text { participants in total } \\
\text { (4 interactive group } \\
\text { sessions with } 3 \\
\text { dispensers, } 5 \text { checkers } \\
\text { and } 13 \text { managers) }\end{array}$} & Learning and action items \\
\hline $\begin{array}{l}\text { 4. Evaluation of } \\
\text { modelling } \\
\text { approach }\end{array}$ & $\begin{array}{l}\text { Questionnaire and } \\
\text { focus group } \\
\text { discussions }\end{array}$ & & $\begin{array}{l}\text { Perceived usability, utility and } \\
\text { applicability }\end{array}$ \\
\hline
\end{tabular}

The participatory process produced an interactive web-model that is composed of three interactive scenarios. Although we summarise the purposes of the scenarios and the main findings; further in-depth details of the three scenarios are discussed elsewhere (Ibrahim Shire 2018; Ibrahim Shire et al. 2019).

Scenario 1 examines the impact of staffing level on efficiency (backlog) and safety (dispensing errors). The main lessons for this scenario reveal that flexible staffing arrangements are less effective than equivalent-fixed staffing arrangement and that delayed calling of extra staff and early discharge of same staff can have a substantial effect on backlog.

Scenario 2 looks at the impact interruptions have in terms of production. The main lessons from Scenario 2 include interruptions by trainees (up to 20 percent of 
prescriptions) have a negative impact on the self-checking performance of fully qualified staff (5-10 percent reduced capacity) and that a tipping point (60 percent of prescriptions) induces significant backlog that forces qualified staff to finish two hours later.

Scenario 3 illustrates how capacity and dispensing errors are affected by fatigue caused by high workload. The main lesson derived from Scenario 3 is that continuous high workload for more than two hours induces fatigue which gradually reduces the total capacity of qualified and introduces more dispensing errors. In Stage 4, outputs from the simulation-based scenario testing from the Stage 3 were presented to participants facilitate discussion about potential implications these results have might in relation to staff management.

One example of the interactive dashboard consisting of scenario setting and simulation outputs is presented in Figure 1. It illustrates how users create varied scenarios to test (right side of Figure 1) and compare the outcomes for different combinations of selected interventions (left side of Figure 1). Figure 1 scenario examines the impact of staffing level on efficiency (backlog) and safety (dispensing error). The dashboard provides additional functions to assess the impact of interruptions on production and the impact of high workload and fatigue on capacity and errors, but the dashboard examples for the additional functions are not included in this paper but are described else (Ibrahim Shire 2018). 


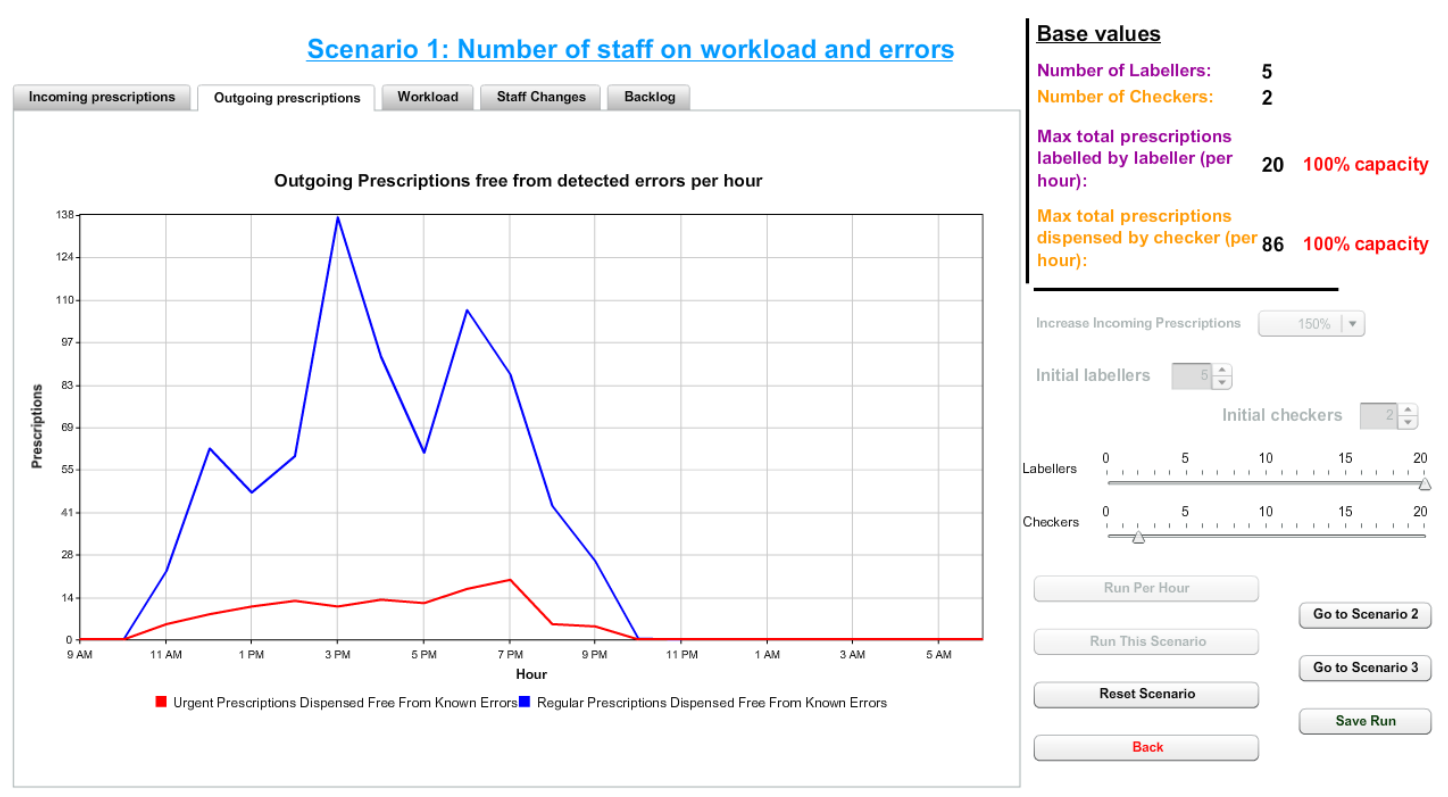

Figure 1. Impact of staffing level on efficiency and safety

\section{Evaluation procedure}

For the purpose of this paper, data for the evaluation was gathered during the multiple stages of the participatory SD approach. For data triangulation, participant observation and stakeholders' interviews during group sessions were used to collect information: i. Pre-group model building interviews $(n=9)$; ii. Post-group model building interviews $(n=13)$; iii. Interactive group sessions observations and questionnaire $(n=21)$.

Transcripts from the semi-structured interviews and observation notes were qualitatively analysed and discussed in detail below.

\section{Data collection for evaluation}

Participants' perspectives were gathered from semi-structured interviews, questionnaire, and group discussions (Stage 1-3) wherein their perceptions were captured that looked at the

- Utility of participatory SD approach as a decision support tool

- Usability of the simulation modelling tool for use within hospital pharmacies

- Strengths and limitations of the participatory SD approach 
At Stage 4, we conducted four interactive group sessions lasting between 90 minutes and 2 hours and involving 21 stakeholders (in total) including dispensers ( $n=$ $3)$, checkers $(n=5)$ and managers $(n=13)$. The primary purpose of these sessions was to evaluate the final interactive simulation dashboard model. During these sessions, the output results from the dashboard were discussed, and a discussion ensued on the perception of the approach and how it can potentially impact their hospital pharmacy practice and healthcare in general. After the session, a questionnaire (see appendix 1) was handed out to the participants who were asked to complete it. The questionnaire was composed of a set of questions with a 5-point Likert-type scale ranking from 1 to 5 , giving an ordinal, non-metric measurement. Other types of questions included are rank order/multiple, single select (yes/no) questions and open-ended questions. The structure of the questionnaire included, but not limited to, the following themes: model complexity and understanding; validity; usefulness; views about the simulation results. The questionnaire was reviewed by individual researchers and senior hospital pharmacists for face validity and all indicated they found that the questionnaire does reflect the intended objectives.

\section{Data analysis}

Audio-recorded interviews and group discussions were transcribed by first author. The first author undertook coding and analysis of the transcriptions. The analysis was guided by grounded theory principles (Charmaz 2014). Analytical memos were developed throughout the coding process that explored the themes identified in the questionnaire, and to triangulate insights from the interviews, group discussions and questionnaires. The coding was iteratively reviewed and revised accordingly based on the finding of new data. 


\section{Evaluation results}

This section presents the evaluation results of participant perspectives on the applicability of the participatory SD approach. The first subsection will look at the utility of the participatory SD approach by presenting views of stakeholders concerning pre-modelling perceptions, perceived usefulness, complexity and validity. The second subsection will present the results of the usability of the approach by looking at the ease of understanding of the model concerning decision-making and group-learning.

\section{Perceived Utility of participatory SD approach}

Twenty-one participants at Stage 4 were asked to express their opinions as to the following three aspects of usefulness: i) enhance learning; ii) think strategically; iii) facilitate communication. Both the conceptual model (i.e. non-animated causal loop diagrams) and the simulation model (i.e. animated interactive dashboard) were created, presented and used with dispensers and management in this study.

Interestingly, the conceptual model was considered equally important when it comes to the utility as the simulation model by both dispensers and managers. Half of the dispensers thought the conceptual diagram was the most important model whereas the other half selected the simulation model. Similarly, 54 percent of the managers selected simulation as the most important model and 46 percent selected the conceptual model. On the oter hand, the overall responses from the dispensers and the managers were different. Sixty seven percent of the dispensers responded that the models were useful whereas only 41 percent of the managers thought they were useful. It was stated that one of the main reasons for managers' less positive view about the model's perceived usefulness is their limited confidence in the validity of the model due to lack of their involvement in the initial stage of the group model building (Stage 1-3). 
The model was initially constructed through iterative discussions with a group of dispensers and aimed to reflect their reality. This contributed to the development of the ownership of the model by those involved, thereby indicating the high confidence in the model's validity amongst dispensers. Dispensers highlighted that their active involvement in the participatory modelling and simulation process increased their familiarity and trust in the model and simulation outputs. Managers, on the other hand, were ambivalent about the validity of the model and argued that the level of dispensing error reporting requires further validation.

When validating the model with dispensers, one of the dispensers highlighted that the model reflects a genuine feedback loop between various bottlenecks and increased dispensing errors being reported. A checker who was involved in the initial group model building corroborated the model validity by adding a delay and multiple interactions in the dynamics of the staff workload management.

"The staffing levels have always been the same, but the workload has increased. Just because we're doing the work doesn't mean we are not suffering from high workload. If they increase capacity on the ward let's say they add 30 patients, we don't have the immediate resources to cope with it and then we are asked to do extra, and that is where problems start. We are continuously stretched, and it never changes... So, the model shows that incoming prescriptions, interruptions and fatigue all impact us at the same time which makes sense, especially the impact on workload."

(Checker)

When dispensers were asked how participatory SD approach enhanced their learning and impacted their current practices, they specified that their participation in the modelling and simulation changed their reductive and reactive way of approaching issues in the dispensary into a more holistic and proactive way.

"...having a visual representation of workload/time and its effect would enable proactive approach"

(Dispenser)

"It allowed me to see the whole level of complexity... It's for this reason why we need a holistic approach where we look at the full picture, and this model made me think about it in a more systematic way. You got to think from all the areas, 
ward to store to dispensing team. You can expand the model and its scope. For instance, if you've storekeepers working below the capacity, how will that affect the dispensary. "

(Data Manager)

Respondents valued the learning experience, what they learned from both the process as well as the output. The model was perceived as a valuable communication tool thereby lending credibility as an useful decision-making tool. Most (95.5 percent) reported that the participation helped them gain a better understanding of one another, the hospital pharmacy dispensary system, and the impact of incorrect staffing levels, workload, interruptions and fatigue on the well-being of the hospital pharmacy dispensers. Dispensers and checkers who represent the sharp end of the system expressed confidence that the simulation model reflected their shared mental model of the hospital pharmacy dispensary system.

"I particularly enjoyed the experience to learn how the model can benefit and positively impact on the dispensary. Throughout the process, it helped me connect with my colleagues on different areas that I previously was not aware of."

(Dispenser)

Respondents highlighted how this particular model might be useful in different settings and other hospital pharmacy dispensaries. Many have reported positively that this approach can be useful as a tool for learning and anticipating the output, especially as a policy-making tool.

"I like the fact that I can simply manipulate one or two variables and instantly visualise their implication on the overall system. It's a useful policy-making tool. I like it."

(Manager)

The management group forwarded several answers when asked how the model might impact on their respective department. Several managers mentioned that the SD model might be useful in adjusting the level of staff against workflow by proactively managing the level of capacity and demand. Others stated that by considering the 
number of staff, additional workers could be pulled through the dispensary in anticipation in order to make the best use of skilled workforce. Others voiced that the simulation model requires more extended scenarios in order to understand how periphery departments impact their departments.

Participants highlighted one limiting factor which is that the current model takes into account the generic average capacities of two types of staff groups -- dispensers and checkers -- which process at 100 percent capacity around 20 and 86 prescriptions per hour respectively, as obtained from literature and observations. Taking into account, for instance, the different working capacities of trainees, starters, pre-registration pharmacists would enable them to test scenarios with different types of skill sets and in order to determine the impacts on backlog and errors.

"It is quite difficult to capture an individual's performance. Everyone in the dispensary is different and has various levels of training, various levels of experience, and everyone works at different speeds...if you split your dispensers down into different groups, trainees might get an increase in the number of questions being asked whilst skilled staff don't. If you add those groups, it might give you a different result and perhaps allows us to see a greater efficiency if we change which groups of staff we can utilise."

(Senior Checker)

Commonly reported reasons for level of comprehensiveness varied amongst dispensers and managers. In general, the dispensers perceived the dispensary model as fully comprehensive in its reflection of the actual generic dispensary, highlighting that the model contains the level of necessary detail found in all UK hospital pharmacies. The management group, however, differed on the level of comprehensiveness with many mentioning that it was not comprehensive enough. In principle, managers perceived the SD model as somewhat comprehensive since all the components of the SD model were not explicitly presented on the interactive dashboard, however, this can be explained that given the management group was composed of assorted participants 
with different backgrounds and in charge of similar dispensary departments, each had a different mental model view of what level of detail the model should encompass.

Both groups emphasised their awareness in the need to ensure that model outputs were interpreted appropriately and that assumptions and limitations of data of the model should be clearly communicated.

\section{Perceived Usability of participatory SD approach}

The participants in this study were asked about their levels of understanding of multiple aspects: the overall model structure; the relationship between variables; how to use the model and the interactive simulation dashboard; how to interpret the simulation outputs. The levels of understanding for each of these items were measured on a Likert-type scale of 1 to 5, where one means 'very little' and five means 'very well'. The aim is to measure the participants' perceived understanding of the models (see the questionnaire sections 2 and 3).

As for the ease of understanding of the conceptual model, half of the participants (both dispensers and managers) responded positively. For the simulation model, 91 percent of the dispensers/checkers responded positively while 54 percent of the managers responded positively.

One of the respondents, a checker, described below how (s)he tried to understand the conceptual model and the interactive simulation dashboard.

"It gave me a clearer picture, and you could see it as it went throughout the day. With the conceptual diagrams, you could not stare at it as a full picture, so you have to follow the variables and look at the polarities to make sense of it. You have to spend quite some time and read it to get some insights, but looking at all those closed loops could be information overload.

With the graph in the interactive simulation dashboard, you can automatically see where it goes up and down, and visually it gave me more information in a snapshot. you can see an increase in workload, an increase in errors, and decrease in staff and so on."

(Checker) 


\section{Discussion}

The aim of this paper is to explore the perspectives of healthcare workers who participated in a participatory SD approach in terms of their perceived utility and usability of this method as a learning and decision support tool in a hospital pharmacy context. The results and feedback from stakeholders suggest that participatory modelling process and its outputs (i.e., the conceptual model and the interactive simulation dashboard) are important instruments for enhancing social learning and promoting a shared and better understanding of complex problems within healthcare. In general, the scenario-based simulation results could aid planning and policy choices within the hospital pharmacy sector to improve staffing level management, cost-benefit analysis, and proactively reduce dispensing errors and backlog.

\section{Utility of the participatory SD approach}

One interesting finding was that the participants considered the conceptual model (i.e. causal loop diagram) as important as the simulation model. The conceptual model visualised complex interactions between multiple causal factors, which is in contrast with linear and reductive analysis often carried out in their internal incident investigation reports (Peerally et al. 2017). The participants emphasised that the conceptual model should be continually used, improved and expanded so it enhances their learning experience.

The participants found the conceptual model useful since it illustrated the negatively reinforcing interactions between incoming prescriptions, staffing levels, interruptions, fatigue, backlog, workload, error and rework. For example, the conceptual model revealed how the capacity shortage of dispensers and checkers, directly and indirectly, affects various factors, which in turn viciously increase their workloads. The 
participants discovered that the conceptual model enabled them to better envision the role of multiple key factors in a larger context than they normally think. These findings agree with Sedlacko et al. (2014) who argue that conceptual diagrams are perhaps the most employed communication and visualisation tools for participatory reflection and knowledge sharing.

Conversely, the simulation model (i.e. interactive simulation dashboard) helped the participants to capture additional dynamics in the model and show the quantitative relationship between staffing levels and backlog. The dashboard allowed the participants to assess the effect of organisational decision-making on efficiency and safety. The simulation dashboard helped the participants change assumptions and test its impact without time-consuming understanding of the intricacies of the underlying calculations that are highly complex.

A significant majority of the participants (78.5 percent) in this study felt that the simulation model is a credible, relevant and consistent representation of the reality on the ground. It can therefore be assumed that the simulation model can be accepted and used to enhance in-depth understanding of the dynamic overview of staff capacity and demand which meets the need Berwick (2013) identified. This decision support tool based on dynamic understanding of capacity and demand can help the hospital pharmacy management to anticipate, monitor and respond to demand-capacity misalignments, which is one of the important resilience attributes (Anderson et al. 2020).

The participant's remark also demonstrates that the interactive simulation dashboard is an apt tool for illustrating the impacts of workload pressure and its contributory factors and helping people to learn more about staff workload management. The group discussion with the management at Stage 4 reconfirmed that 
the simulation model can aid with management decision-making and suggested to expand the model with additional parameters to cover a wider system boundary or transfer it to different healthcare units with similar problems.

The use of the interactive simulation dashboard led to an extensive discussion among the participants. For example, staffing level shortage, increased workload and fatigue, increased dispensing error, increased rework and increased workload were acknowledged to be a main loop that can have a reinforcing impact on the system performance. An extensive debate was instigated on how such vicious-impact-creating factors can be mitigated. It was evident from the discussion on simulation result interpretation that the managers were fascinated in adopting the model as a tool for policy analysis. Some of them remarked that they were still willing to trial policies that the model presented to be desirable whilst observing and learning from the underlying behaviour.

The common thread identified from the participants' discussion was that the web-based interactive interface was considered helpful and easy to interpret. The participants mentioned how both the conceptual and simulation models clearly illustrate how the interconnectedness of the output and the importance of each other. They added how the web interface undoubtedly aided to visualise the complexity and made it easier to understand what was happening.

The participants indicated that they have learned from the participatory SD modelling process and particularly from the different interpretations that their coparticipants had. Several participants highlighted that the modelling process and accompanying discussions added greater value and insight to their knowledge and expertise. 
Many highlighted how the interactive simulation dashboard could be useful in many other settings. The participatory SD process and the interative simulation dashboard can be useful and extended to other applications such as another dispensary and healthcare facilities, e.g., aseptic dispensing units, pathology labs or facilities with safety-efficiency trade-offs, where the differences in parameters could be negligible and therefore could take advantage from the transferable knowledge generated by dynamic analysis of this abstract model. Altogether, the participants found involvement of the group model building process and the interactive simulation dashboard-based discussion on the results were mainly very beneficial. Consequently, all participants expressed appreciation for the opportunity to discuss workload problems in a structured manner, reflecting on their knowledge, opinions, views, values, perspectives, and interests. Many voiced their inclination to participate in any future SD participatory modelling sessions within healthcare. Two recent studies that applied participatory SD modelling in healthcare echoed similar experiences (Weeks et al. 2017; Zimmerman et al. 2016b).

One of the most frequent criticisms levelled against participatory SD approach is that stakeholders become disconnected with the whole modelling process. They either feel that their participation in the sessions is nominal (Voinov and Bousquet 2010), or they sometimes view the modelling process as too complex that might hinder them from actively participating in the development process (Newig et al. 2008). The questionnaire used in this study to examine the usability and utility reveal that the participants thought their contribution was appreciated and they thoroughly enjoyed the process. This outcome indicates that the participatory SD approach can be very practical when both usability and utility aspects are well managed and incorporated. 


\section{Usability of the participatory SD approach}

One of the many factors that determine the usability of a method is its ease of use. However, the weight placed upon this factor will be very subjective. Some might reject a method that has various practical difficulties as being useless whilst others might accept these challenges as an inevitable part of the process of deriving important insights - a 'no pain, no gain' attitude. SD modellers argue that the benefits of participatory SD modelling can be considerable since they claim that it allows participants to learn the linkage between the structure of a system and its behaviour and how that relates to long-term success or failure of an intended action (Sterman 2004; Senge 1990).

Building structures in front of or with participants tend to teach participants more about the basics of conceptual model building. We taught the participants the basics of the conceptual model building which may have accomplished two aspects relevant to the process. First, it helps establish trust in the model and an appreciation of model transparency. Second, it helps stakeholders to understand systems thinking. Those who are accustomed to viewing the world in a linear manner may benefit from the system thinking exercise.

In this study, managers were not part of the initial group model building sessions and the formulation of the conceptual model and they found it more challenging to understand and claim ownership of the simulation model as opposed to dispensers who were part of the early sessions. Furthermore, among the participants who were not part of the initial group building session, participants in small-sized groups ( 3 to 5) found it much easier to comprehend and use the simulation model than participants in large groups (10+). The participants in this study remarked that being in small-sized groups and playing directly with the interactive dashboard allowed them to ask useful questions 
to comprehend the model and have the ability to play around with it. On the other hand, the participant in large groups did not have the similar level of opportunities.

Conducting simulation model exercise in small-sized groups tend to be more effective in healthcare and incorporating and engaging stakeholders from the get-go will allow them to understand the model building process much easier (Holtgrave and Pinkerton 1998; McCree, Eke, and Williams 2007).

\section{Lessons learned on modelling facilitation}

The participatory SD modelling approach adopted in this study taught us key lessons that are important and applicable to the overall application and design of future SD modelling exercises. The participatory SD framework is often regarded to be a resource (and time) intensive (Voinov et al. 2016). In our study, this was most reflected in the analysis of qualitative data. Working face-to-face with groups of stakeholders and repeating the process each time took a significant amount of time, mainly from participants as they had to adhere to a strict work schedule. Thus, it is imperative to assign a degree of flexibility and adjustment to the methodology, depending on the number of stakeholders and the level of engagement. For instance, in the model evaluation sessions (Stage 4 in Table 1), it was much easier and manageable to split groups into small-sized groups (groups of 4) and test the model with them. Given that hospital pharmacies are already fraught with workload pressure, the small-sized groups proved to be convenient for the dispensaries team leaders since the number of absent staff in the hospital dispensaries that were kept to a minimum.

Frequent communication with the participants is particularly meaningful when involving assorted types of healthcare practitioners to co-develop an SD model. We detected early on that formulating a quantitative diagram and designing the Forio web interface can be very time-consuming. In this study, it took around 12 months due to the 
nature of the sessions taking place in groups and the first author's initial unfamiliarity with the process. As a result, there is a continual need to gauge the interests of stakeholders throughout the modelling process. Moreover, there is a need to tread lightly so as not to overload stakeholders with information and questions but at the same time not being too detached. Understandably, people can get easily disengaged once overloaded with communication. Conversely, being too detached can generate the same effect. In general, although it is preferable to plan each session in detail, it is essential to be flexible during each session, to listen to the participants' intents and desires as the participants are the facilitator's customers.

The role of the facilitator cannot be fully predetermined and may have to be adapted according to the idiosyncrasies of the group. The diversity of the group members and their interrelationships, as well as the facilitator's style, necessitate the need to understand the group's life by being flexible and accommodating to the needs of the group members (Clawson, Bostrom, and Anson 1993). The facilitator needs to improve through a learning process that can turn him/her into a more mature and experienced guide who can fully understand the needs of the group members (Atwell 2006).

\section{Limitations and future research}

The study focused on one case study which was a hospital pharmacy in Leicestershire, England. Thus, the views and perspectives of participants were limited to the aforementioned case study and will inevitably affect generalisability. Secondly, given the finite time with participants who were adhering to a strict busy schedule, there was limited participation of stakeholders in all aspects of the process. For instance, developing the initial custom simulation dashboard development was conducted by the 
first author instead of in a participatory manner albeit the interactive simulation model was tested, revised and validated by participants. This was attributed due to lack of time to arrange further sessions with participants. Although participants found the participatory SD model building useful for group learning, decision-making and priority setting, a future focus would be in implementing the same process in other hospital dispensaries to identify similar contextual results.

\section{Conclusion}

The overarching purpose of this paper was to report on the perspectives of hospital pharmacy managers and dispensers, who participated in a participatory SD study. We evaluated their perceptions of the utility and usability of participatory modelling and simulation as a tool for decision support for managing staffing levels at hospital pharmacies.

The evaluation results and feedback from the participants have provided new insights into the experience of engaging in participatory SD modelling. The results suggest that both the conceptual model and the simulation model are equally important to the participants in gaining a deeper understanding of the complex interactions, enhancing team learning, supporting consensus agreement and setting priority. This study strengthens the idea that it is important to get the stakeholders involved in from the early group-based conceptual model-building stage to give them a sense of ownership and credibility to the simulation model. The findings also suggest that smallsized group engagement (3-5 participants) is more effective than large-sized group engagement $(10+$ participants $)$ in supporting their understanding and use of the simulation model. In general, this study suggests that the participatory SD approach could aid planning and policy choices within the hospital pharmacy sector to support 
safer and more efficient staffing level management, in other words, proactively reduce dispensing errors and backlog.

However, it was noted that implementing a participatory SD process is not trivial. Consequently, several challenges and lessons can be derived from using this approach within the greater health sector. These include: the importance of preliminary interviews at the start model building, being aware that the modelling objective could be changed and dictated by stakeholders, involving a manageable number of participants, keep the model output as generic as possible and devoting enough time for model quantification and simulation.

Acknowledgements

Authors would like to thank Chief Pharmacist Claire Ellwood and the staff at University Hospitals of Leicester (UHL) for their support throughout this study. 


\section{References}

Anderson, J. E., A. J. Ross, C. Macrae, and S. Wiig. 2020. "Defining Adaptive Capacity in Healthcare: A New Framework for Researching Resilient Performance.” Applied Ergonomics. https://doi.org/10.1016/j.apergo.2020.103111.

Atkinson, Jo-An, Robert Wells, Andrew Page, Amanda Dominello, Mary Haines, and Andrew Wilson. 2015. “Applications of System Dynamics Modelling to Support Health Policy." Public Health Research \& Practice 25 (3): 1-8. https://doi.org/10.17061/phrp2531531.

Atwell, Ryan C. 2006. "Mediated Modeling: A System Dynamics Approach to Environmental Consensus Building.” Landscape Ecology. https://doi.org/10.1007/s10980-005-5569-5.

Berwick, Don. 2013. “A Promise to Learn-a Commitment to Act: Improving the Safety of Patients in England." London: Department of Health 6. https://www.gov.uk/government/uploads/system/uploads/attachment_data/file/226 703/Berwick_Report.pdf.

Brailsford, Sally. 2005. "Overcoming the Barriers to Implementation of Operations Research Simulation Models in Healthcare." Clinical and Investigative Medicine. Médecine Clinique et Experimentale 28 (6): 312-15. http://www.ncbi.nlm.nih.gov/pubmed/16450620.

Charmaz, K. 2014. Constructing Grounded Theory. https://books.google.com/books?hl=en\&lr=\&id=v_GGAwAAQBAJ\&oi=fnd\&pg= $\mathrm{PP} 1 \& \mathrm{dq}=$ Constructing + grounded + theory\&ots $=$ YWZzN7Cyl2\&sig=SzAgm3 hBt V3EiQeMu_-LoN9j30. 
Clawson, Victoria K., Robert P. Bostrom, and Rob Anson. 1993. "The Role of the Facilitator in Computer-Supported Meetings." Small Group Research. https://doi.org/10.1177/1046496493244007.

Cousins, David H., David Gerrett, and Bruce Warner. 2012. “A Review of Medication Incidents Reported to the National Reporting and Learning System in England and Wales over 6 Years (2005-2010).” British Journal of Clinical Pharmacology. https://doi.org/10.1111/j.1365-2125.2011.04166.x.

Dul, Jan, Ralph Bruder, Peter Buckle, Pascale Carayon, Pierre Falzon, William S. Marras, John R. Wilson, and Bas van der Doelen. 2012. “A Strategy for Human Factors/Ergonomics: Developing the Discipline and Profession.” Ergonomics 55 (4): 377-95. https://doi.org/10.1080/00140139.2012.661087.

Eldabi, T, R J Paul, and T Young. 2006. "Simulation Modelling in Healthcare: Reviewing Legacies and Investigating Futures.” Journal of the Operational Research Society 58 (2007): 262-70.

https://doi.org/10.1057/palgrave.jors.2602222.

Eldabi, Tillal. 2009. "Implementation Issues of Modeling Healthcare Problems: Misconceptions and Lessons." In Proceedings of the 2009 Winter Simulation Conference (WSC), 1831-39. IEEE. https://doi.org/10.1109/WSC.2009.5429192.

Faezipour, Misagh, and Susan Ferreira. 2013. “A System Dynamics Perspective of Patient Satisfaction in Healthcare.” Procedia Computer Science 16: 148-56. https://doi.org/10.1016/j.procs.2013.01.016.

Fone, D, and S Hollinghurst. 2003. "Systematic Review of the Use and Value of Computer Simulation Modelling in Population Health and Health Care Delivery.” 
Journal of Public .... http://jpubhealth.oxfordjournals.org/content/25/4/325.short.

Foster-Fishman, Pennie G., and Teresa R. Behrens. 2007. "Systems Change Reborn: Rethinking Our Theories, Methods, and Efforts in Human Services Reform and Community-Based Change.” American Journal of Community Psychology 39 (34): 191-96. https://doi.org/10.1007/s10464-007-9104-5.

Gilbert, Nigel, Petra Ahrweiler, Pete Barbrook-Johnson, Kavin Preethi Narasimhan, and Helen Wilkinson. 2018. “Computational Modelling of Public Policy: Reflections on Practice.” JASSS. https://doi.org/10.18564/jasss.3669.

Hettinger, Lawrence J., Alex Kirlik, Yang Miang Goh, and Peter Buckle. 2015. "Modelling and Simulation of Complex Sociotechnical Systems: Envisioning and Analysing Work Environments.” Ergonomics 58 (March): 1-15. https://doi.org/10.1080/00140139.2015.1008586.

Hewitt, Richard, Hedwig Van Delden, and Francisco Escobar. 2014. "Environmental Modelling \& Software Participatory Land Use Modelling, Pathways to an Integrated Approach.” Environmental Modelling and Software 52: 149-65. https://doi.org/10.1016/j.envsoft.2013.10.019.

Hollnagel, Erik. 2009. The ETTO Principle: Efficiency-Thoroughness Trade-Off, Why Things That Go Right Sometimes Go Wrong. Risk Analysis. Vol. 30. Ashgate. https://doi.org/10.1111/j.1539-6924.2009.01333.x.

Holtgrave, David R., and Steven D. Pinkerton. 1998. "The Cost-Effectiveness of Small Group and Community-Level Interventions.” In , 119-26. https://doi.org/10.1007/978-1-4899-1878-9_8. 
Ibrahim Shire, Mohammed. 2018. "Participatory System Dynamics Modelling Approach to Safe and Efficient Staffing Level Management within Hospital Pharmacies." Loughborough University. Loughborough University.

Ibrahim Shire, Mohammed, Gyuchan Thomas Jun, Seongam Moon, and Stewart Robinson. 2019. “A System Dynamics Approach to Workload Management of Hospital Pharmacy Staff: Modeling the Tradeoff between Dispensing Backlog and Dispensing Errors." IISE Transactions on Occupational Ergonomics and Human Factors, January, 1-30. https://doi.org/10.1080/24725838.2018.1555563.

Ibrahim Shire, Mohammed, Gyuchan Thomas Jun, and Stewart Robinson. 2018. "The Application of System Dynamics Modelling to System Safety Improvement: Present Use and Future Potential.” Safety Science 106 (July): 104-20. https://doi.org/10.1016/j.ssci.2018.03.010.

Jacobs, Sally, Sheena Johnson, and Karen Hassell. 2018. "Managing Workplace Stress in Community Pharmacy Organisations: Lessons from a Review of the Wider Stress Management and Prevention Literature.” International Journal of Pharmacy Practice. https://doi.org/10.1111/ijpp.12360.

Jahangirian, Mohsen, Aisha Naseer, Lampros Stergioulas, Terry Young, Tillal Eldabi, Sally Brailsford, Brijesh Patel, and Paul Harper. 2012. "Simulation in Health-Care: Lessons from Other Sectors.” Operational Research. https://doi.org/10.1007/s12351-010-0089-8.

James, K. Lynette, Dave Barlow, Rowena McArtney, Sarah Hiom, Dave Roberts, and Cate Whittlesea. 2009. "Incidence, Type and Causes of Dispensing Errors: A Review of the Literature.” International Journal of Pharmacy Practice 17 (1): 9- 
30. https://doi.org/10.1211/ijpp/17.1.0004.

Jones, Natalie A., Pascal Perez, Thomas G. Measham, Gail J. Kelly, Patrick D’Aquino, Katherine A. Daniell, Anne Dray, and Nils Ferrand. 2009. "Evaluating Participatory Modeling: Developing a Framework for Cross-Case Analysis." Environmental Management. https://doi.org/10.1007/s00267-009-9391-8.

Jun, Gyuchan Thomas, Aneurin Canham, Ander Altuna-Palacios, James R. Ward, Ran Bhamra, Stephen Rogers, Amalin Dutt, and Priyal Shah. 2018. “A Participatory Systems Approach to Design for Safer Integrated Medicine Management.” Ergonomics. https://doi.org/10.1080/00140139.2017.1329939.

Katsaliaki, K., and N. Mustafee. 2011. "Applications of Simulation within the Healthcare Context." Journal of the Operational Research Society. https://doi.org/10.1057/jors.2010.20.

McCree, Donna Hubbard, Agatha Eke, and Samantha P. Williams. 2007. "Dyadic, Small Group, and Community-Level Behavioral Interventions for STD/HIV Prevention." In Behavioral Interventions for Prevention and Control of Sexually Transmitted Diseases, 105-24. Boston, MA: Springer US. https://doi.org/10.1007/978-0-387-48740-3_4.

Mutingi, Michael, and Charles Mbohwa. 2012. "Dynamic Simulation of Healthcare Manpower Systems: A Market-Based Perspective.” In 760: 761: 762: 763: The IASTED 2012 African Conferences. Calgary,AB,Canada: ACTAPRESS. https://doi.org/10.2316/P.2012.761-007.

Newig, Jens, Helmut Haberl, Claudia Pahl-Wostl, and Dale S. Rothman. 2008. "Formalised and Non-Formalised Methods in Resource Management-Knowledge 
and Social Learning in Participatory Processes: An Introduction." Systemic

Practice and Action Research 21 (6): 381-87. https://doi.org/10.1007/s11213-0089112-x.

Peerally, Mohammad Farhad, Susan Carr, Justin Waring, and Mary DIxon-Woods. 2017. "The Problem with Root Cause Analysis." BMJ Quality and Safety. https://doi.org/10.1136/bmjqs-2016-005511.

Pesce, Julianna E., Chinwe S. Kpaduwa, and Marion Danis. 2011. "Deliberation to Enhance Awareness of and Prioritize Socioeconomic Interventions for Health.” Social Science \& Medicine 72 (5): 789-97. https://doi.org/10.1016/J.SOCSCIMED.2011.01.002.

Proudlove, N C, S Black, and A Fletcher. 2007. "OR and the Challenge to Improve the NHS: Modelling for Insight and Improvement in in-Patient Flows." Journal of the Operational Research Society 58 (2): 145-58. https://doi.org/10.1057/palgrave.jors.2602252.

Salmon, Paul M., and Gemma J.M. Read. 2019. "Many Model Thinking in Systems Ergonomics: A Case Study in Road Safety.” Ergonomics. https://doi.org/10.1080/00140139.2018.1550214.

Schafheutle, Ellen Ingrid, Elizabeth Mary Seston, and Karen Hassell. 2011. "Factors Influencing Pharmacist Performance: A Review of the Peer-Reviewed Literature.” Health Policy 102 (2-3): 178-92. https://doi.org/10.1016/j.healthpol.2011.06.004.

Sedlacko, Michal, Andre Martinuzzi, Inge Røpke, Nuno Videira, and Paula Antunes. 2014. "Participatory Systems Mapping for Sustainable Consumption: Discussion of a Method Promoting Systemic Insights.” Ecological Economics 106 (October): 
33-43. https://doi.org/10.1016/J.ECOLECON.2014.07.002.

Seidl, Roman. 2015. “A Functional-Dynamic Reflection on Participatory Processes in Modeling Projects.” Ambio 44 (8): 750-65. https://doi.org/10.1007/s13280-0150670-8.

Senge, PM. 1990. "The FIfth Discipline: The Art and Practice of the Learning Organization." New York: Currency Doubleday. https://scholar.google.co.uk/scholar?q=senge $+1990 \& b \operatorname{tnG}=\& h \mathrm{~h}=$ en\&as_sdt $=0 \% 2 \mathrm{C}$ $5 \# 1$.

Service, National Health. 2018. "Monthly Data on Patient Safety Incident Reports." The National Reporting and Learning System (NRLS). 2018.

Stave, Krystyna A. KA. 2002. “Using System Dynamics to Improve Public Participation in Environmental Decisions.” System Dynamics Review 18 (2): 13967. https://doi.org/10.1002/sdr.237.

Sterman, John D. 2004. Business Dynamics: Systems Thinking and Modeling for a Complex World. McGraw-Hill.

Underwood, Peter, Patrick Waterson, and Graham Braithwaite. 2016. ““Accident Investigation in the Wild' - A Small-Scale, Field-Based Evaluation of the STAMP Method for Accident Analysis." Safety Science 82: 129-43. https://doi.org/10.1016/j.ssci.2015.08.014.

Vennix, Jac A.M. 1999. “Group Model-Building: Tackling Messy Problems.” System Dynamics Review 15 (4): 379-401. https://doi.org/10.1002/(SICI)10991727(199924)15:4<379::AID-SDR179>3.0.CO;2-E. 
Vennix, Jac A.M., David F. Andersen, George P. Richardson, and John Rohrbaugh. 1992. "Model-Building for Group Decision Support: Issues and Alternatives in Knowledge Elicitation.” European Journal of Operational Research. https://doi.org/10.1016/0377-2217(92)90005-T.

Voinov, Alexey, and Francois Bousquet. 2010. "Modelling with Stakeholders." Environmental Modelling and Software 25 (11): 1268-81. https://doi.org/10.1016/j.envsoft.2010.03.007.

Voinov, Alexey, Nagesh Kolagani, Michael K. McCall, Pierre D. Glynn, Marit E. Kragt, Frank O. Ostermann, Suzanne A. Pierce, and Palaniappan Ramu. 2016. “Modelling with Stakeholders - Next Generation.” Environmental Modelling \& Software 77 (March): 196-220. https://doi.org/10.1016/J.ENVSOFT.2015.11.016.

Weeks, Margaret R., Jianghong Li, David Lounsbury, Helena Danielle Green, Maryann Abbott, Marcie Berman, Lucy Rohena, Rosely Gonzalez, Shawn Lang, and Heather Mosher. 2017. "Using Participatory System Dynamics Modeling to Examine the Local HIV Test and Treatment Care Continuum in Order to Reduce Community Viral Load." American Journal of Community Psychology 60 (3-4): 584-98. https://doi.org/10.1002/ajcp.12204.

Young, Terry, Julie Eatock, Mohsen Jahangirian, Aisha Naseer, and Richard Lilford. 2009. “Three Critical Challenges for Modeling and Simulation in Healthcare.” In Proceedings - Winter Simulation Conference. https://doi.org/10.1109/WSC.2009.5429186.

Zimmerman, Lindsey, David W. Lounsbury, Craig S. Rosen, Rachel Kimerling, Jodie A. Trafton, and Steven E. Lindley. 2016a. "Participatory System Dynamics 
Modeling: Increasing Stakeholder Engagement and Precision to Improve

Implementation Planning in Systems." Administration and Policy in Mental Health and Mental Health Services Research 43 (6): 834-49.

https://doi.org/10.1007/s10488-016-0754-1.

. 2016b. "Participatory System Dynamics Modeling: Increasing Stakeholder Engagement and Precision to Improve Implementation Planning in Systems.” Administration and Policy in Mental Health and Mental Health Services Research 43 (6): 834-49. https://doi.org/10.1007/s10488-016-0754-1. 


\section{Appendix 1 - Questionnaire}

\section{Personal details}

1. What is your role in the dispensary? Please specify whether you are a student or not.

\begin{tabular}{|l|l|}
\hline$\square$ Dispenser & $\square$ Checker \\
\hline$\square$ Other (Please specify):
\end{tabular}

2. What is your level of experience (in years)?

3. Have you ever used a simulation model before?

$\square$ Yes (Please specify):

$\square$ No

II. Opinion about the dispensary simulation model

\section{a. Model understanding\& complexity}

Please answer the following questions based on your experience of running the dispensary simulation model in the group. The aim of this set of questions is to assess how comprehensive the model provided was.

1. How well do you feel you understand how the non-animated model works?

\begin{tabular}{|l|l|l|l|l|l|l|}
\hline Understand very little & $\square 1$ & $\square 2$ & $\square 3$ & $\square 4$ & $\square 5$ & Understand very well \\
\hline
\end{tabular}

2. Please specify to what extent you feel you understand the following parts of non animated the model? a. The relationship between variables

\begin{tabular}{|c|c|c|c|c|c|c|}
\hline Understand very little & $\square 1$ & $\square 2$ & $\square 3$ & $\square 4$ & $\square 5$ & Understand very well \\
\hline \multicolumn{7}{|c|}{ b. The structure of the model } \\
\hline Understan & $\square 1$ & $\square 2$ & $\square 3$ & $\square 4$ & $\square 5$ & Understand very well \\
\hline
\end{tabular}

3. Please specify to what extent you feel you understand the following parts of animated the model? a. How to use the model

\begin{tabular}{|c|c|c|c|c|c|c|}
\hline Understand very little & $\square 1$ & $\square 2$ & $\square 3$ & $\square 4$ & $\square 5$ & Understand very well \\
\hline \multicolumn{7}{|c|}{ b. Model outputs/results } \\
\hline Understand very little & $\square 1$ & 2 & $\square 3$ & 4 & $\square 5$ & Understand very well \\
\hline
\end{tabular}

4. According to the level of importance, please rank from 1 to 3 , where 1 is most important and 3 least important, which of the following factors, helped you understand the model?
a. Non-animated description of model (Casual Loop)
b. Visual interface of the model (Web Interface)
c. Animation as the model runs (Web Interface)

5. How would you rate the level of detail of the dispensary model?

\begin{tabular}{|l|l|l|l|l|l|l|}
\hline Very comprehensive & $\square 1$ & $\square 2$ & $\square 3$ & $\square 4$ & $\square 5$ & Very abstract
\end{tabular}


b. Model validity

This section deals with your opinion about the credibility of the dispensary simulation model.

1. To what extent do you feel the simulation model is representative of the dispensary system?

\begin{tabular}{|l|l|l|l|l|l|l|}
\hline Very little & $\square 1$ & $\square 2$ & $\square 3$ & $\square 4$ & $\square 5$ & Very much \\
\hline
\end{tabular}

2. To what extent do you feel the model generates realistic outputs?

\begin{tabular}{|l|c|c|c|}
\hline Very little & $\square 1$ & $\square 2$ & $\square 3$
\end{tabular}

$\square 4+\square 5 \quad$ Very much

3. How confident would you feel in using this model for decision making?

\begin{tabular}{|l|c|c|c|c|c|c|}
\hline Very little & $\square 1$ & $\square 2$ & $\square 3$ & $\square 4$ & $\square 5$ & Very much \\
\hline
\end{tabular}

c. Model usefulness

Please answer the following questions with respect to the dispensary simulation model. The aim is to identify the tradeoff about the usefulness of the dispensary simulation model.

1. To what extent do you feel using the dispensary simulation model enhanced your learning about causes of dispensing errors?

\begin{tabular}{|l|l|l|l|l|l|l|}
\hline Very little & $\square 1$ & $\square 2$ & $\square 3$ & $\square 4$ & $\square 5$ & Very much \\
\hline
\end{tabular}

2. To what extent do you feel using the dispensary simulation model helped you think strategically about dispensing errors

\begin{tabular}{|l|l|l|l|l|l|l|}
\hline Very little & $\square 1$ & $\square 2$ & $\square 3$ & $\square 4$ & $\square 5$ & Very much \\
\hline
\end{tabular}

3. In what other contexts might a similar model be used? Please name a few. Why is it relevant?

To what extent do you feel the dispensary simulation model facilitated the communication of ideas and suggestions throughout your group discussion?

\begin{tabular}{|l|l|l|l|l|l|l|}
\hline Very little & $\square 1$ & $\square 2$ & $\square 3$ & $\square 4$ & $\square 5$ & Very much \\
\hline
\end{tabular}

4. Based on what you have learned, how would you impact current practice?

d. Opinion about the simulation results

In this section, we intend to derive your opinion about the results of the dispensary simulation model.

1. How did you find the interpretation of results?

\begin{tabular}{|l|r|l|l|l|l|l|}
\hline Very straightforward & $\square 1$ & $\square 2$ & $\square 3$ & $\square 4$ & $\square 5$ & Very difficult \\
\hline
\end{tabular}

Any further comments? (Please specify):

2. a. On a scale from 1 to 5 , how useful did you find the tables?

\begin{tabular}{|l|l|l|l|}
\hline Very little & $\square 1$ & $\square 2$ & $\square 3$
\end{tabular}

b. What was the main learning point from the tables?

3. a. On a scale from 1 to 5 , how useful did you find the graphs?

\begin{tabular}{|l|l|l|l|}
\hline Very little & $\square 1$ & $\square 2$ & $\square 3$
\end{tabular}

b. What was the main learning point from the graphs?

e. Overall opinion about the simulation model

1. Would you like to make any other comments about the dispensary simulation model? 